CIUDAD Y TERRITORIO

ESTUDIOS TERRITORIALES

ISSN(P): 1133-4762; ISSN(E): 2659-3254

Vol. LII, № 204, verano 2020

Págs. 295-306

https://doi.org/10.37230/CyTET.2020.204.07

CC BY-NC 4.0

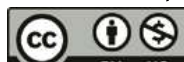

\title{
Metáforas de la modernidad: Mario Pani en México
}

\section{Alfonso ValenZuela-Aguilera}

Profesor Investigador Titular C, Universidad Autónoma del Estado de Morelos

RESUMEN: La metáfora es una figura retórica utilizada para hacer comprensible un fenómeno mediante imágenes de otro orden que permiten representarlo. Si consideramos que las ciudades son asentamientos humanos inmersos en complejos sistemas funcionales y ambientales sería razonable que hayan sido representadas mediante analogías y metáforas biológicas a lo largo de la historia del urbanismo. Examinando las referencias utilizadas para explicar el funcionamiento de las ciudades en la primera mitad del siglo veinte, encontramos que entre los importantes urbanistas utilizaron metáforas organicistas se encuentra el mexicano Mario Pani (1911-1993), que se consolidaría como uno de los exponentes más avanzados de las ideas urbanísticas de la modernidad y como responsable de haber diseñado soluciones urbanas que definieron el perfil de la Ciudad de México en la primera mitad del siglo XX.

PALABRAS CLAVE: Metáforas; Modelos urbanos; Modernidad; Visionarios.

\section{Metaphors of modernity: Mario Pani in Mexico}

ABSTRACT: The metaphor is a rhetorical figure used to make a phenomenon understandable by means of images of another order that allow it to be represented. If we consider that cities are human settlements immersed in complex functional and environmental systems, it would be reasonable for them to have been represented by analogies and biological metaphors throughout the history of urbanism. Examining the references used to explain the functioning of cities in the first half of the twentieth century, we find that among the important urbanists used organic metaphors is the Mexican Mario Pani (1911-1993), who would consolidate himself as one of the most advanced exponents of urban planning ideas of modernity and as responsible for having designed urban solutions that shaped Mexico City's profile in the early $20^{\text {th }}$ century.

KEYWORDS: Metaphors; Urban models; Modernity; Visionaries.

Recibido: 16.01.2019; Revisado: 17.06.2019

Correo electrónico: aval@uaem.mx NºRCID: https://orcid.org/0000-0003-3238-446X

El autor agradece los comentarios y sugerencias realizados por los evaluadores anónimos, que han contribuido a mejorar y enriquecer el manuscrito original. 


\section{La metáfora como instrumento de aproximación a la ciudad moderna}

a metáfora fue utilizada desde la Grecia antigua para transferir significados mediante el uso de palabras. Mediante este vehículo de transferencia de significados es que la metáfora puede considerarse como un dispositivo de pensamiento y acción (LAKOFF \& JOHNSON, 1980, 3). De acuerdo con Nuessel, la metáfora es un

"dispositivo cognitivo usado para explicar cómo las personas categorizan la realidad y almacenan las abstracciones de esa existencia física en su cerebro" $(2010,230)$.

Las metáforas tienen una larga historia en el ámbito urbano y surgen frente los grandes cambios tecnológicos en donde el lenguaje cotidiano resulta insuficiente para transmitir la complejidad de las nuevas realidades. Es así que desde la revolución industrial comienzan a utilizarse las metáforas sobre la ciudad referidas como máquinas, como organismos vivos o bien, utilizando imágenes más abstractas como los textos, la música, o los tejidos. En este trabajo sostenemos que Mario Pani utilizó distintas metáforas como las supermanzanas, las células urbanas, las ciudades satélite o la ciudad universitaria para transmitir conceptos urbanos complejos durante la etapa de industrialización acelerada que se dio en esos años en México.

Uno de los primeros intérpretes de la ciudad moderna fue el sociólogo, educador y biólogo Patrick Geddes (1854-1932), quien combinaría estas disciplinas en su concepción urbanística, utilizando para ello metáforas sobre el crecimiento desbordado de las nacientes metrópolis en "Ciudades en Evolución" (1915), comentaba al respecto:

"Las ciudades ahora deben dejar de extenderse como manchas de tinta y manchas de grasa en expansión: una vez que alcancen un desarrollo real, repetirán la apertura en forma de estrella de la flor, con hojas verdes en alternancia con sus rayos dorados." (GeDDEs, 1915: 97)

Geddes adoptaría las ideas evolucionistas de Charles Darwin -a quien conoció en el University College de Londres- aplicándolas al análisis urbano y superando el paradigma desarrollista que consideraba a las ciudades como organismos limitados de modo que las relaciones entre los elementos que las conforman tendrían una relación abierta, interdependiente y con un final impredecible. Así, comentaba:
"El lugar, el trabajo y el entorno popular, la función y el organismo ya no se ven separados, sino como elementos de un proceso único de vida saludable para el individuo y la comunidad." (GedDES, 1915: 198).

Por otra parte, urbanistas como Lewis MUMFORD (1938) argumentaban que la ciudad se constituía como un organismo formado por "cromosomas sociales" que tendrían en su interior información específica sobre sus límites y dimensiones máximas, lo cual no alcanzaría a capturar la esencia del fenómeno urbano. A partir de esta visión, se desarrollaría la práctica de elaborar planos urbanos con el fin de "ordenar" el espacio e incluso frenar el crecimiento, sin llegar a comprender los fenómenos territoriales y económicos que permiten vincular la forma espacial con las dinámicas y procesos sociales, pasando con ello por alto el planteamiento evolutivo de Geddes sobre los finales abiertos.

La metáfora organicista sería recurrente en la mayoría de urbanistas de la época, incluyendo al mismo Le Corbusier, quien reconocería que la ciudad podía concebirse como un "fenómeno biológico" (1933: 194); del mismo modo que Josep Lluís Sert que sería uno de los principales ideólogos del CIAM (Congresos Internacionales de Arquitectura Moderna):

"Las ciudades son organismos vivos; nacen y se desarrollan, se desintegran y mueren. [...] En su sentido académico y tradicional, la planificación urbana se ha vuelto obsoleta. En su lugar debe ser sustituida por la biología urbana" (SERT, 1942)

Es probable que las ideas de Le Corbusier no hubieran alcanzado tal resonancia internacional de no haber sido por los CIAM. Creados con el fin de promover ideas espaciales y constructivas de vanguardia, tenían como fin último transformar la sociedad por medio de la arquitectura. La visión academicista consistente en proveer un hábitat adecuado al hombre se transformó en la creación de un entorno moderno al cual deberían ajustarse los habitantes de la era moderna. El origen de los CIAM se vincula a las ideas del filósofo y teórico social Henri de Saint-Simon (1706-1825), quién sostendría que los avances científicos y tecnológicos darían lugar a un nuevo sistema social de corte humanista.

Por su parte, Mario Pani destacaba por ser un gran estudioso de los planteamientos urbanísticos de vanguardia y conocía de primera mano las intervenciones que en muchas de las capitales europeas se estaban poniéndose en marcha. Si bien Pani comprendió que las ciudades mexicanas tendrían que adecuarse a las necesidades 
de la vida moderna, también era consciente de los peligros de un crecimiento desbordado que atentaban contra los espacios de calidad y convivencia. Como refiere sobre el trabajo del arquitecto finlandés Eliel Saarinen,

"[Saarinen], con plausible actitud contemporánea, incorpora en sus planes los conceptos de la célula orgánica de Camilo Sitte, las áreas expandidas han formado una masa única, pero heterogénea, con un grave proceso de congestión desorganizada [...] Es quien, por primera vez, propone una cirugía decisiva, operando transfusiones de vida en las áreas aún libres del contagio, trasladando las actividades de zonas decadentes a lugares funcionalmente apropiados, para rehabilitar después las áreas vacantes, como en el caso de Chicago" (PANI, 1957: 209).

La importancia de los espacios públicos estuvo ligada a la provisión de condiciones saludables para la población y como garante de las funciones comunitarias de socialización de la población. El arquitecto alemán Walter Gropius coincidía con Le Corbusier en el sentido que las construcciones de altura proveerían la densidad necesaria para alcanzar

"las importantes ventajas biológicas de mayores cantidades de luz y asoleamiento, mayores distancias entre los edificios colindantes y la posibilidad de proveer parques externos articulados, así como áreas infantiles de juego entre los bloques [..]" (GROPIUS, 1950: 116).

Le Corbusier, en cambio, argumentaría a favor de la ciudad densa ya que las grandes concentraciones urbanas generaban "manifestaciones de extrema vitalidad" y por tanto

"[...] en principio la ciudad es necesariamente un lugar de encuentro, de contacto, de competencia y conflicto entre energía diversas", y que, no obstante, sería contraproducente dispersar dichas energías atraídas de manera natural (COHEN, 1992:139).

De acuerdo con le Corbusier, la ciudad compactada gracias a las nuevas tecnologías aseguraba al individuo un cierto grado de libertad para organizar su vida colectiva en torno a la recreación. Además, plantea en sus cinco "resoluciones de principio" (producto del CIAM 4, 1933), que:

"[...] los elementos materiales que el urbanismo puede acomodar y combinar son el cielo, los árboles, la vivienda, los lugares de trabajo, los espacios colectivos (que incluyen los espacios de recreación) y el tráfico" (Le CoRbusier, 1967:188).
Pani tuvo una influencia consistente y duradera de las ideas de Le Corbusier a lo largo de su carrera, por lo que es pertinente abundar acerca de las bases de las que partió. Ambos apostaron hasta el final de sus días por elevadas densidades urbanas en sentido vertical, combinadas con un complejo sistema de circulación vial y permitiendo grandes extensiones de espacios verdes circundando los edificios. Le Corbusier haría las propuestas más radicales que incluirían la demolición de partes considerables del tejido histórico de la ciudad -argumentando su disfuncionalidad-, para ser sustituidas por desarrollos espaciales geométricos y estandarizados. Ya desde los primeros prototipos de ciudad planteada en el Plan Voisin ${ }^{1}$, Le Corbusier propondría un espacio diferenciado, dividido y finalmente segregado para cada uno de los niveles socioeconómicos de pertenencia: torres centrales de gran altura para industriales, profesionistas y artistas como élite dominante, mientras que de manera análoga al modelo ecologista de la Universidad de Chicago, los distintos estratos socioeconómicos se agruparían de manera descendente del centro hacia las periferias, dejando en estas últimas a los obreros agrupados en "células urbanas", un concepto que Pani habría de retomar con fuerza más adelante.

A partir de la década de los veinte, Le Corbusier (1929) plantearía su visión urbana alejándose de la idea organicista y adoptando la metáfora maquinista:

"Nunca debemos perder de vista en nuestros estudios la 'célula' humana perfecta. Debemos llegar a la casa-máquina, la cual debe ser satisfactoria tanto en sentido práctico como emocional y diseñada para una sucesión de inquilinos. La idea del 'hogar antiguo' tiende a desaparecer y con ella la arquitectura local, etc., dado que el trabajo cambiará de acuerdo con las necesidades del momento, por lo que [el residente] deberá estar listo para mudarse en cualquier momento."

Le Corbusier seguiría afinando según su visión urbana sobre los nuevos espacios de la modernidad, y de acuerdo con FISHMAN (1977: 239) destacaba en el marco de la Ciudad Radiante que:

"La ciudad armónica debe ser primeramente planeada por expertos quienes entiendan la ciencia del urbanismo. Ellos producen los planes en total libertad, ajenos a presiones partidistas e intereses particulares; una vez que los planes han sido formulados, estos deben implementarse sin oposición."

\footnotetext{
1 Le Corbusier siempre tuvo una pasión por los aviones y la aeronáutica, escribiendo al respecto, e incluso diseñando dicho plan para un fabricante de aviones.
} 


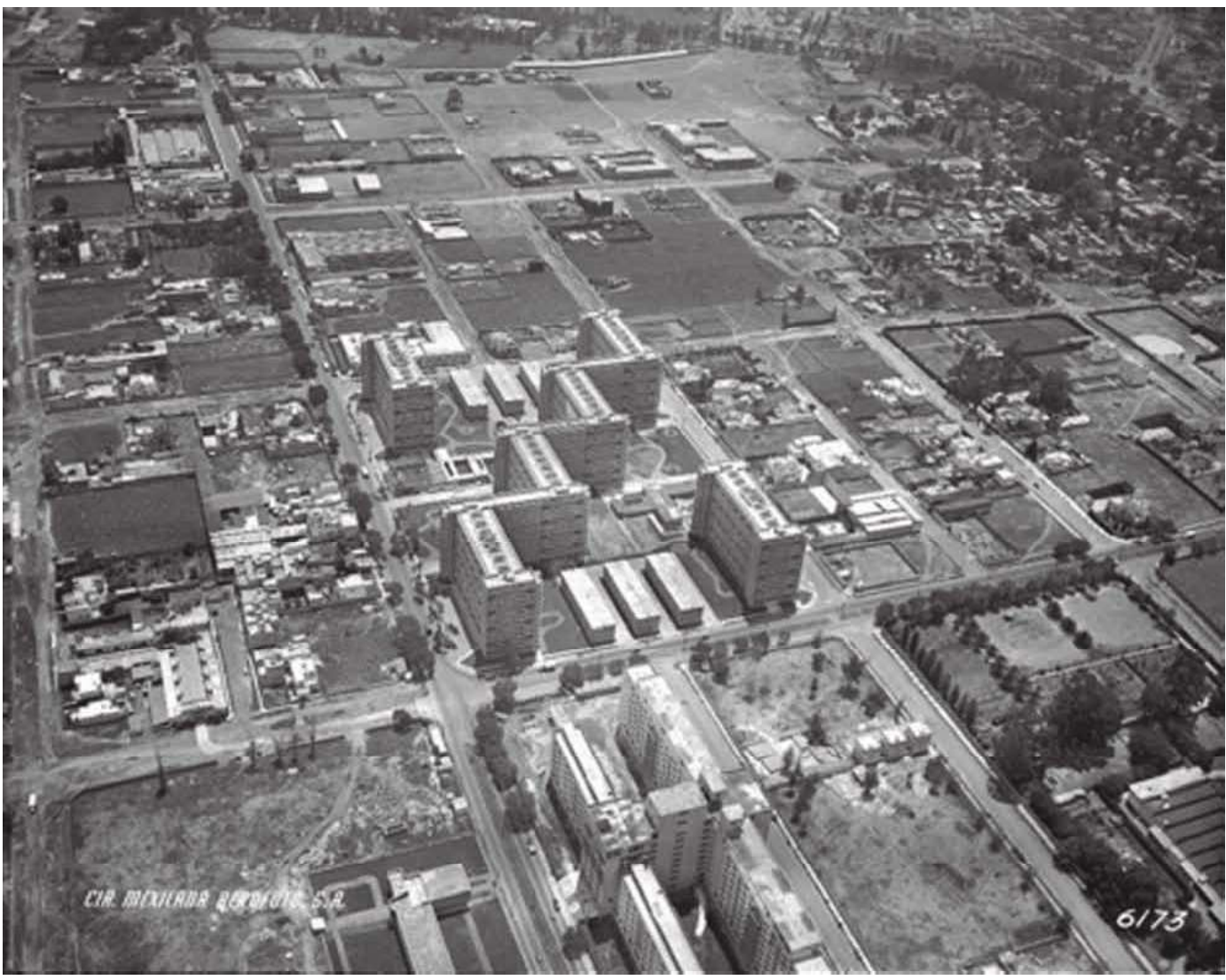

FIG. 1/ Centro Urbano Presidente Miguel Alemán, vista aérea 1949.

Fuente: ICA-Aerofoto.

Sin embargo, Pani tenía sus reservas con respecto a dicha propuesta, cuestionando la viabilidad de diseñar una ciudad ideal en donde la complejidad de los procesos humanos no quedara reflejados ni resueltos:

"Es una solución ideal, para un mundo ideal, de ilimitados recursos económicos; que serviría a hombres y núcleos humanos capaces de olvidar las piedras y las obras en que está escrita su historia y fraguada su tradición; que fueran iguales en necesidades, en aspiraciones, en actitud frente a la vida; y que se avinieran a residir en una colmena gigantesca, prodigiosa e idealmente organizada" (PANI, 1957: 209).

La planeación comenzó a ser visualizada como un ejercicio de poder, así como un acto de control jerárquico y centralizado, justificado quizás por el aura del cientificismo. Dicho ejercicio de la planeación sólo podría tener lugar en regímenes totalitarios, por lo que no es de extrañar que Le Corbusier haya intentado de manera indistinta de conseguir comisiones y adherentes con los regímenes tanto de Stalin como Mussolini, e incluso están documentadas sus negociaciones con el general Pétain, durante la ocupación alemana de Francia, con sede en la ciudad de Vichy, y a quien ofreció sus servicios para crear las nuevas ciudades del régimen (Fox WEBER, 2008).

\section{La Supermanzana como modelo de organización social y espacial}

El problema de la vivienda social sería abordado por Pani a lo largo de su carrera, siguiendo como referentes a los arquitectos del CIAM y comenzando por analizar la dimensión económica y social de la cuestión: dado que los sectores más desfavorecidos no estaban en posibilidades de adquirir una vivienda, entonces se hacía necesaria la intervención del Estado mediante subsidios. Mientras que originalmente se habían definido estándares constructivos y espaciales 
para asegurar el confort del usuario, ahora eso se convertía en una cuestión de mínimos, ya que los ahorros se traducirían en un mayor número de viviendas y los derroches en una mayor injusticia social.

Habiéndose ocupado de la problemática habitacional durante varias décadas en distintos proyectos entre los que se contaban el Centro Urbano Presidente Alemán, la Unidad Modelo No. 9 en Iztapalapa, así como las Unidades Vecinales de Tlacotal, Bramadero, Centinela y Modelo (Guadalajara), Mario Pani traería, por primera vez, a discusión el tema de vivienda a la revista Arquitectura/México, subrayando el hecho que el suyo era un planteamiento inédito, operativo e innovador De acuerdo con sus argumentos, una parte medular para la solución del problema consistía en potencializar la capacidad de ahorro de la clase media, ya que

"la capacidad de ahorro, inexistente en los estratos más bajos de la sociedad, no es todavía suficiente aún en la clase media, para costearse alojamientos del tipo que requiere" (GómEz,1949: 67-74).
Dentro del pragmatismo que lo caracterizaba, Pani parecía haber descubierto una fórmula infalible para la adquisición de vivienda mediante un esquema de ahorro: el $25 \%$ de capital acumulado en un fondo se completaba con una hipoteca equivalente al $75 \%$ restante. De acuerdo con sus cálculos, si dicho esquema se replicaba de manera masiva el potencial derivado sería capaz de

"modificar radicalmente nuestra vida urbana y doméstica, es decir, de iniciar una transformación de ilimitado alcance" (GómEz,1949: 68).

Si bien el sistema de financiamiento mediante el esquema de ahorro y préstamo llevaba varias décadas funcionando en los países industrializados, Pani consideraba que más que transferir un esquema debian buscarse soluciones que integraran de manera orgánica la economía con la arquitectura, abordando los problemas mediante soluciones colectivas.

Pani utilizaría también dos conceptos clave que marcaría su trabajo profesional: las unidades vecinales y las supermanzanas ${ }^{2}$. Mientras que las

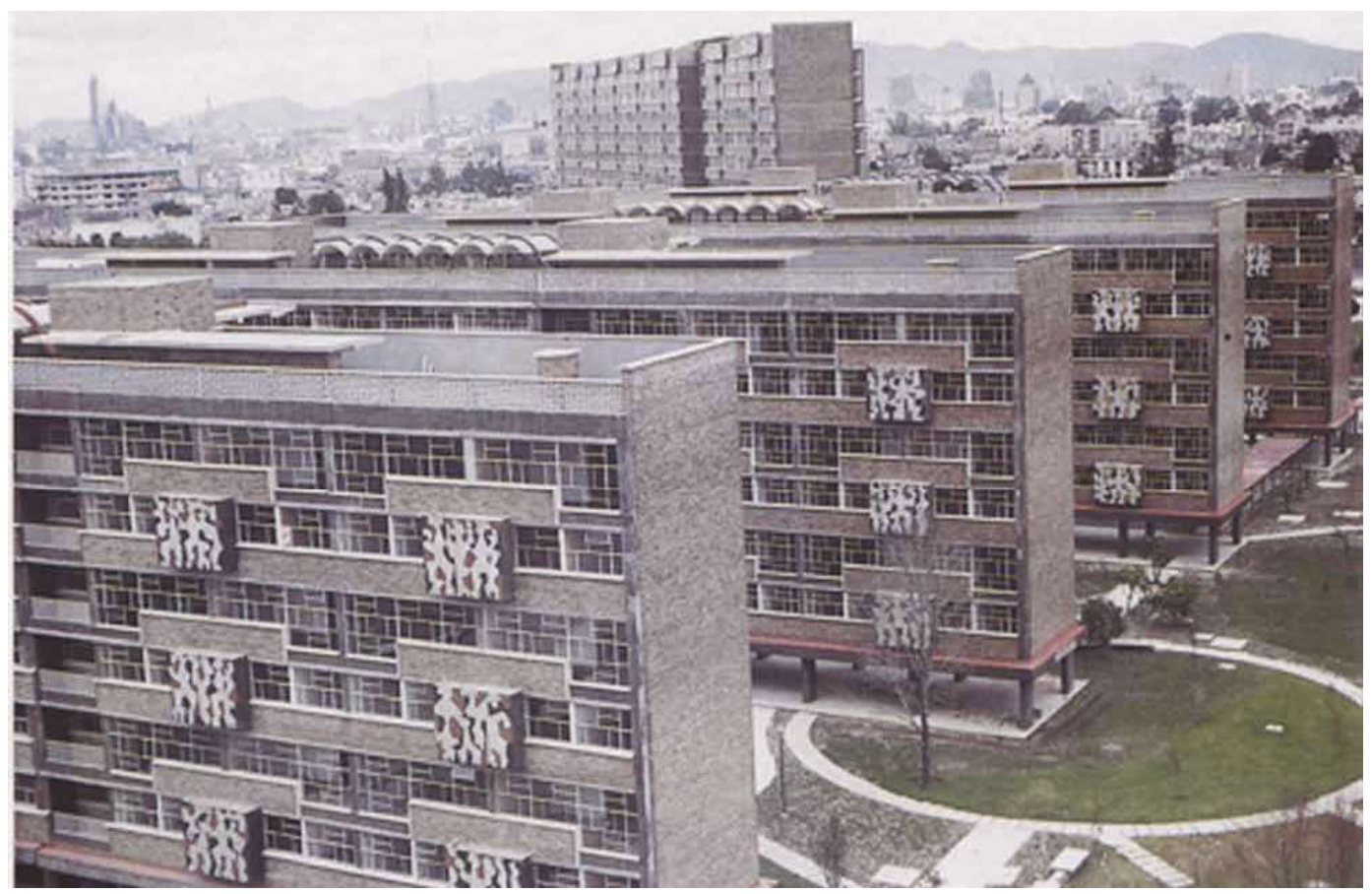

FIG. 2/ Mario Pani, Multifamiliar Juárez.

${ }^{2}$ Las Supercuadras son definidas como un núcleo urbano de alta densidad que integraría vivienda unifamiliar, duplex y multifamiliar al interior de un parque urbano separado del tráfico vehicular y realizado como una comunidad. 
primeras sirvieron como base conceptual para la promoción de la vida social, las supermanzanas fueron la materialización física de dicha base en los desarrollos de Sunnyside, Radburn y Greenbelt, así como de los centros urbanos diseñados por el arquitecto. En cambio, las unidades vecinales serían concebidas por Clarence Perry durante la elaboración del Plan Regional para la ciudad de Nueva York y sus Alrededores de 1922, en donde se priorizaría la vida comunitaria a contracorriente de la tendencia generalizada por planear en función del automóvil.

Perry se interesaría por escudriñar los elementos constitutivos esenciales de la comunidad, de acuerdo con un estudio que realizó acerca de los distritos escolares y sus vecindarios, observó que los individuos buscaban más allá de una vivienda agradable "un entorno atractivo, buenas escuelas, juegos infantiles y tiendas de conveniencia", lo cual no resultaba fácil de encontrar (PERRY, 1912: 124-133). Si bien esta noción fue aceptada, Perry destacaba que los ingenieros al construir las redes de bulevares, vías-parques y autopistas estaban creando profundos y extensos canales que cortaban las zonas residenciales rodeadas de flujos vehiculares (PerRY, 1912: 99). Por lo que consideraba que tanto los residentes como los peatones debían ser protegidos mediante el esquema de Unidades Vecinales, el cual funcionaría como una "célula habitacional protegida". Utilizando como ejemplo los "suburbios-jardín" de Forest Hills Gardens, Sunnyside Gardens y el pionero Hampstead Garden Suburb de Londres, Perry proponía la Unidad Vecinal como un conjunto de principios de planeación dirigidos a la organización comunitaria.

Sin embargo, también observaría una serie de lineamientos, cuyas bondades son discutibles en la actualidad: primeramente, apuntaba que su esquema tendría como efecto la homogenización de la comunidad al acceder a un tipo particular de población, lo cual para la época era considerado como una segregación poblacional natural acorde con criterios raciales, económicos, sociales y vocacionales como parte de un "proceso normal y algo en constante reproducción", que sin embargo requeriría una revaloración como fenómeno social existente (PERRY, 1912: 99). Segundo aspecto, su esquema preveía la formación de grupos primarios, en donde las necesidades compartidas generarían de manera natural la formación de asociaciones, de modo que a fin de cuentas la interacción cara a cara llevaría más lejos las iniciativas de protección mutua hacia objetivos sociales y culturales de mayor aliento (PERRY, 1912: 100). De acuerdo con Perry, el tejido social podría quedar en riesgo al momento en que comenzaran a borrarse los límites (confines) del asentamiento, y la población comenzara a dispersarse, desarticulándose asi los filamentos que mantienen la cohesión de la comunidad local (PERRY, 1912: 98-100).

De acuerdo con el eminente urbanista Lewis Mumford, la solución a los problemas de la ciudad moderna se encontraría en el modelo concebido por Ebenezer Howard medio siglo atrás (Mumford, 1951: 5). En el contexto inmediato de la posguerra, las ciudades jardín, las nuevas ciudades inglesas y el exitoso prototipo de Radburn se posicionarían nuevamente como una alternativa para los esfuerzos de reconstrucción a gran escala. Si bien Mumford había sido invitado a presentar las experiencias acerca de las dos comunidades en Estados Unidos, el urbanista reconocía abiertamente que la filosofía y experiencia de Gran Bretaña había sido centrada para el desarrollo de las nuevas ciudades en su país.

Sin embargo, la década de los veinte sería muy prolífica para el desarrollo de conceptos en Norteamérica, en especial en el seno de la Regional Planning Association of America o RPAA (Asociación de Planeación Regional de América), en donde se gestarían las ideas que sustentarían el proyecto de Radburn. Cómo explicaría Charles Ascher con relación a las actividades de la asociación

"[...] como podrás imaginar, los problemas centrales de la planeación y sus políticas son de lo más asombroso. Hemos tratado de pedirle a expertos de distintos campos que vengan a discutir dichos problemas -y no necesariamente responderlos, sino sugerir líneas de pensamiento y ponernos en contacto con la gente y las agencias que puedan ayudarnos a responder dichas preguntas" (BIRCH, 1980:425).

Clarence Stein junto con Henry Wright concebirían el plan, el primero relatando que después de la primera posguerra se constituiría la RPAA para discutir modelos de "desarrollo regional, geotecnia, y nuevas comunidades" (MUMFORD, 1951: 21). Stein viajaría entonces a la Gran Bretaña y observaría el extensivo programa de Ciudades Nuevas (New Towns) que venían desarrollando a partir del modelo de ciudad jardín, reconociendo después de dicho viaje que regresaba "como discípulo de Ebenezer Howard y Raymond Unwin" (MUMFORD, 1951: 21). En un inicio la intención de Stein fue hacer una comunidad jardín, pero se encontraron con un problema central:

"la compra de terrenos no pudo ser financiada recientemente rápido para poder evitar que el suelo fuera subsidiado y absorbido por el mercado especulativo" (MUMFORD, 1951: 21). 
Para efectos del presente trabajo, nos interesa descartar que Radburn sería la primera comunidad concebida según el concepto de supermanzanas. La referencia original de ciudades jardín como nodos industriales habría de desaparecer, así como los cinturones verdes, e incluso la población objetivo: los obreros de la época no podían costearse las viviendas, la comunidad se conformaría por oficinistas de clase media de modo que "Radburn tuvo que aceptar el rol de suburbio" (MUMFORD, 1951: 44). Si bien el proyecto habría de ser reconocido como un fracaso financiero -en buena parte por causa del inicio de la gran depresión económica- se demostró como el prototipo del nuevo estilo de vida norteamericano de la ciudad moderna, el cual tendría un impacto definitivo en los nuevos desarrollos alrededor del mundo.

El modelo tenía como puntos centrales los siguientes: 1. La utilización de las supermanzanas en sustitución de la manzana clásica, rectangular y estrecha; 2 . La diferenciación de vías de acuerdo con su uso (movimiento, recolección, servicio, estacionamiento y visitas); 3 . La separación absoluta entre el peatón y el automóvil, utilizando para ello distintos niveles para evitar cruzamientos en las intersecciones; 4. La utilización de dos frentes habitacionales de manera que tanto las estancias como las habitaciones tuvieran vistas hacia los parques y jardines circundantes, y 5 . El uso del parque como la columna vertebral del vecindario, con amplios espacios abiertos en el centro de las supermanzanas unidos, a su vez, por un parque continuo (MUMFORD, 1951: 44).

Descrita como una "ciudad para la era motorizada" Radburn utilizaría como base del proyecto el concepto de supermanzanas. Dado el uso extensivo del automóvil en Estados Unidos, Stein y Wright optarían por proponer manzanas de $30 \times$ 50 acres $(12 \times 20$ ha aproximadamente. $)$, rodeadas de amplias avenidas. Finalmente, Radburn sería juzgado en años subsecuentes no tanto por su ejecución, sino por la fuerza conceptual del plan. En contraparte surgirían en los años sesenta visiones críticas al respecto, en donde

"atacarían la presunción de que un diseño basado en los valores de la clase media pudiera promover el progreso social, además de excluir la participación ciudadana dentro del proceso de planeación" (BIRCH, 1980: 437).

\section{Pani y los modelos de ciudad: lo intraurbano y lo extraurbano}

El proyecto del Conjunto Urbano Nonoalco-Tlatelolco se iniciaría en 1958 con la elaboración de un estudio acerca de la regeneración urbana del centro de la ciudad, así como de la llamada área de tugurios circundante. Comisionado por el entonces director del Instituto Mexicano del Seguro Social, Pani habría realizado estudios exhaustivos acerca de la regeneración urbanística de la ciudad de México, así que el Conjunto Urbano Nonoalco-Tlatelolco sería el prototipo de ciudad "regenerada", higiénica, moderna y verde, incluso sustentable. Haciendo escrupulosos cálculos financieros, así como estudios urbanísticos detallados (densidades, zonificaciones, clasificaciones de suelo, valores catastrales, tipo de vivienda, rangos de renta e ingresos, entre otros), Pani proponía un modelo de crecimiento urbano que serviría para regenerar o renovar el parque habitacional, a la vez que se aumentaba la cantidad de espacios verdes de manera exponencial. La racionalidad era impecable si no se consideraban la especulación inmobiliaria ni los agentes económicos determinantes:

"Para que la Habitación Popular pueda disfrutar de todos los servicios urbanos en términos de alto valor, próximos al centro de la ciudad en los lugares de trabajo, será necesario construir en supermanzanas, mediante verificación en altura, proporcionada a los espacios abiertos y servicios sociales para evitar en el futuro, sobresaturaciones nocivas" (PANI, 1960: 183-224).

Una década después, Pani reflexionaría acerca de su labor como urbanista y creador de los centros urbanos y habitacionales más importantes en los últimos años en México, consolidando su concepto de "célula urbana", lo que significaba localizar nuevos núcleos habitacionales de entre 20,000 y 40,000 habitantes en las afueras de la ciudad para responder de manera racional al crecimiento acelerado de las urbes (PANI, 1973b: 236). La denominada "célula urbana" sería un concepto derivado de la Supermanzana de Stein y Wright, en donde la presencia del automóvil estaría fuertemente acotada, en virtud de que:

"todo se tiene a una distancia peatonal, doscientos o trescientos metros, escuelas, el comercio, la Iglesia, la plaza... y aún los negocios" (PANI, 1973a: 5-7).

Esta situación de proximidad proporcionaría una mayor interacción social: "La gente se conocería, tendría preocupaciones comunes y acción colectiva". Pani sugiere mezclar "dentro de límites razonables" los distintos estratos socioeconómicos para generar una comunidad en la que mediante el adecuado uso de la escala se nombraran conjuntos armónicos que propiciaran la "paz social" (PANI, 1973b: 236). Probablemente, Pani estaría impactado por los hechos de violencia de 1968 , en particular por la masacre de estudiantes llevada a cabo en la Plaza de las Tres Culturas de Tlatelolco, si bien la inestabilidad social 


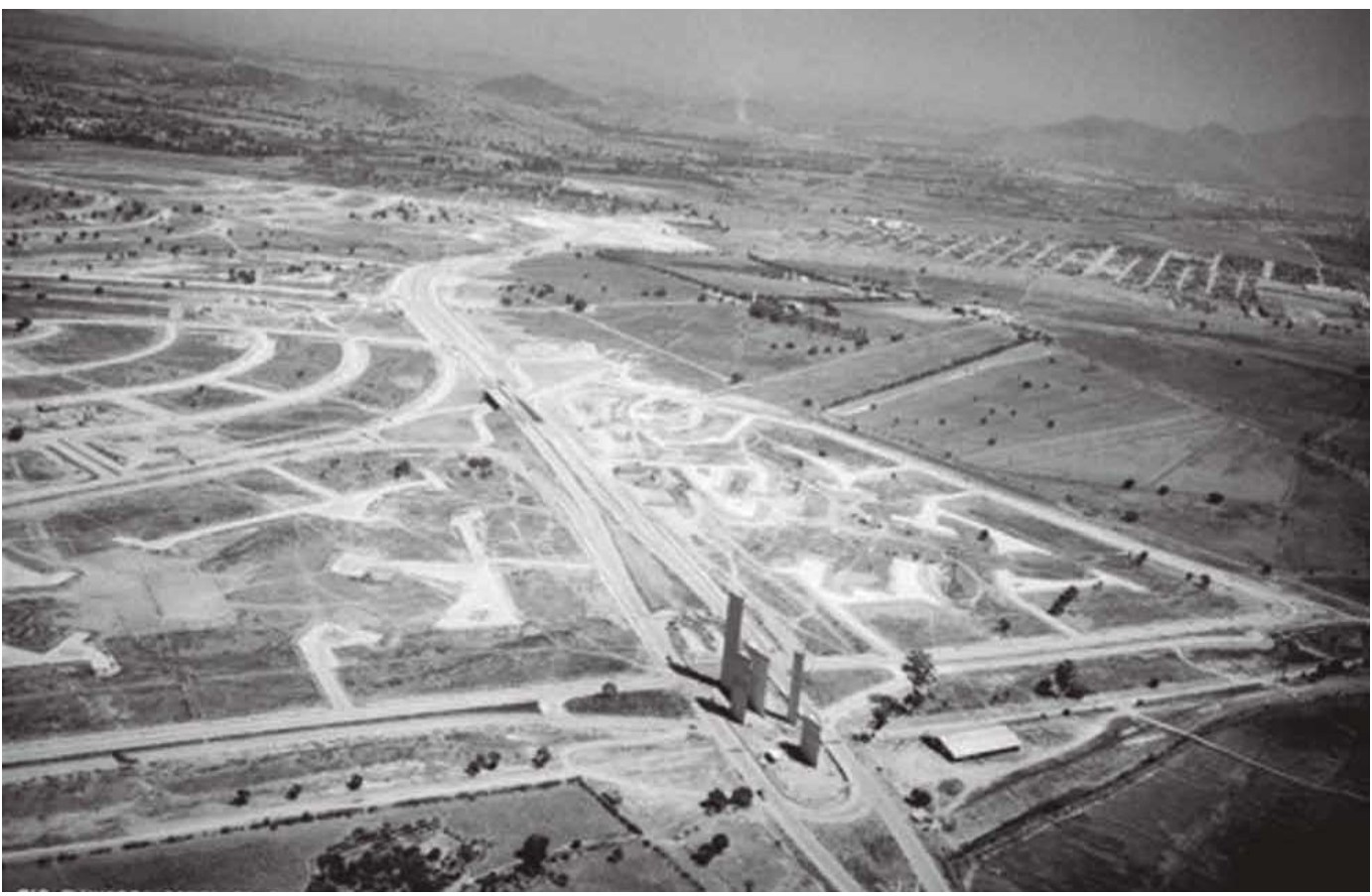

FIG. 3/ Panorama de la nueva Ciudad Satélite, 1957.

continuaría con otro evento similar al de Tlatelolco cerca de otro proyecto de Pani: la Escuela Nacional de Maestros ${ }^{3}$.

Mientras que Tlatelolco representaba la regeneración urbana interna, la "ciudad dentro de la ciudad", la construcción de Ciudad Satélite sería "la ciudad fuera de la ciudad", en donde siguiendo las tendencias suburbanas principalmente de las ciudades norteamericanas, Pani se propondría generar "núcleos urbanos de estructura autónoma", por primera vez, un desarrollo urbano dependería exclusivamente del capital privado para su realización (PANI, 1957: 198-226).

Citando como ejemplos análogos los suburbios londinenses de Stevenage, así como las periferias de Chicago, Mario Pani se lanzaría a la construcción del proyecto Ciudad Satélite sobre un terreno cercano a las ochocientas hectáreas con la ilusión de haber: "concebido y proyectado Ciudad Satélite como una entidad urbana verdaderamente autónoma, como una auténtica ciudad organizada [mediante una] estructura municipal $[\ldots .$.$] ".$

Aun cuando dada la escala del desarrollo se contarían con las provisiones de gestión urbana correspondientes, con el paso del tiempo se haría patente la falta de una visión metropolitana que visualizara la inminente conurbación con el Distrito Federal, mientras que se haría patente la falta de una perspectiva regional que comprendiera las dinámicas socioeconómicas que alteraban el desarrollo de una urbe con los índices de crecimiento de la capital mexicana. Si bien Pani no menciona en ningún momento en sus escritos a Perry, Stein y Wright, hace referencia constante a las supermanzanas habitacionales como "células urbanas" de cerca de 20,000 habitantes, interconectadas mediante parques y organizadas alrededor de un centro cívico, administrativo y comercial, que les conferiría su autonomía funcional.

\footnotetext{
${ }^{3}$ En el primer evento se estima un saldo de 300 estudiantes muertos, mientras en el segundo -conocido como "el Halconazo"- morirían cerca de 120 .
} 
En el esquema original, Pani propondría espacios destinados a edificios multifamiliares de altura y elevada densidad de ocupación; si bien el concepto de generar dinámicas centrípetas de actividades colectivas, en donde idealmente

"el sesenta por ciento de sus habitantes satisfacen dentro de ella la mayoría de sus funciones diarias, sin cruzar la ruta de los automóviles" (PANI, 1957: 218)

La idea inicial de la Ciudad Satélite era, por tanto, una propuesta de carácter social dirigida a la población de recursos medios y bajos, e incluso el centro comercial proyectado estaba pensado como un "centro de tipo comunal", el cual contaría con un edificio especializado para centro de negocios, servicios médicos, cines y teatros. Como prueba de que su concepto se encontraba dentro de la vanguardia internacional, Pani propondría un complejo sistema vial que estaría entre los más avanzados del mundo, organizado mediante arterias viales, anillos de circunvalación y ejes viales, inspirado en un proyecto no realizado del urbanista austriaco Hermann Herrey. Pani tendría siempre puesta la mirada en el futuro:

"[...] concebida Ciudad Satélite con la estructura de una verdadera ciudad moderna, es decir, como una ciudad del futuro, como una ciudad del mañana que empezamos a construir hoy" (PANI, 1957: 225).

Con el optimismo del espíritu moderno, Pani confiaba en que la ciudad planeada y ordenada sería inmune a las dinámicas socioeconómicas, así como a la polarización del ingreso prevaleciente, fenómenos que después se agudizarían y resultarían determinantes para la organización racional de las funciones de la ciudad. De acuerdo con Pani, Ciudad Satélite nunca sería una ciudad anárquica dada la existencia de límites claros -tanto físicos como demográficos-, ya que:

"pocas veces en la historia ha tenido el hombre la oportunidad de planear, proyectar y construir, es decir, de planificar una ciudad desde su arranque, desde los cimientos, para que le fuera permitido, con los medios de que actualmente disponemos, enfrentarse a la problemática y a la previsión de su desarrollo físico y demográfico, económico y social, pudiendo disponer con ello, en anticipo, la solución de los problemas básicos de la convivencia humana" (PANI, 1957: 226).

Por otro lado, Mario Pani tendría muy presente lo que sucedía en aquellos años en Brasil con la creación de la nueva capital, bajo la dirección y concepción del urbanista Lucio Costa, quien utilizaría el modelo de supermanzanas, que agrupadas constituirían las unidades vecinales del mismo modo que Pani propondría para la Ciudad Satélite. De acuerdo con Lins do Rego,
"Le Corbusier fue el punto de partida que permitió a la nueva escuela brasileña expresarse a sí misma con gran espontaneidad y llegar a soluciones originales [...] El regreso a la naturaleza y el valor que provenía de tratar el paisaje como un elemento sustancial, salvó a nuestros arquitectos de lo que podría considerarse formal en Le Corbusier" (XAVIER, 1987).

Comentaba Costa que:

"para conciliar la escala monumental inherente a la parte administrativa con una escala menor, íntima, de las áreas residenciales, imaginé las Supercuadras, -grandes cuadrados con 300 metros de lado-las cuales propuse que estuvieran limitadas a lo largo del perímetro por una faja [verde] de 20 metros de ancho" (COSTA, 1995: 308).

Por su parte, Pani concebiría las supermanzanas como las células que constituyen el total del organismo urbano, que adoptarían usos habitacionales, así como usos especializados: comercial, industrial, escolar, etc., los cuales serían prácticamente autosuficientes de modo que dichos proyectos constituirían "una primera etapa de un programa integral para los problemas de la ciudad de México", para lo cual la solución total sería a partir de una red de comunicaciones de ciudades satélites en México (PANI, 1957: 226).

Si bien Mario Pani argumentaría que las llamadas "células urbanas" deberían ser esencialmente autónomas, al separar el uso residencial de las fuentes de trabajo en realidad estaba por integrarse en la tendencia de "suburbanización",

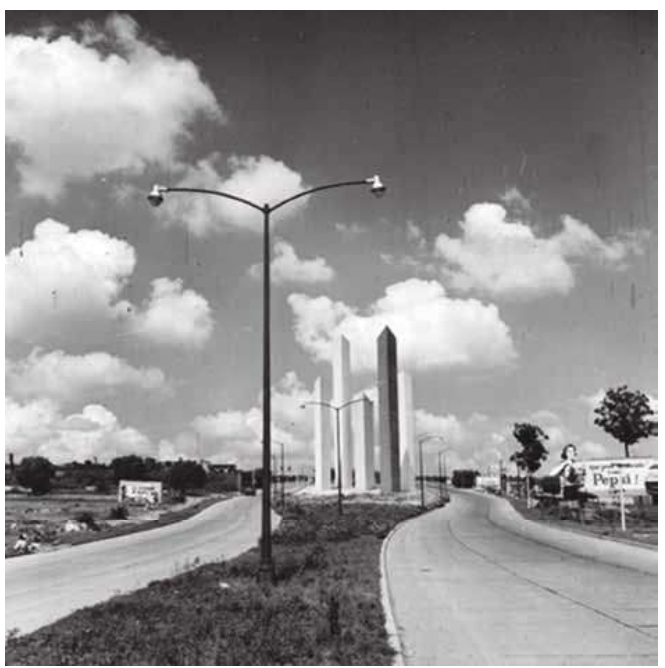

FIG. 4/ Torres de Ciudad Satélite y avenidas, vista general 1958 
que prevalecía ya en las ciudades de los países industrializados. La relación entre las áreas habitacionales y la ciudad, se manifestaría en el tipo de vida de clase media o burguesa, en donde por primera vez una zonificación de usos de suelo separaría las habitaciones de la industria, colocando al comercio en una especie de recinto-ciudadela bordeada por autopistas y rodeada de estacionamientos. Al proponer una red de ciudades satélites, Pani se acercaría al concepto de Clarence Perry que tiene que ver con el modelo de ciudad polinuclear (PERRY, 1929), en donde se hacía patente la importancia de las escuelas, los parques comunitarios, los juegos infantiles y los comercios locales para fortalecer el carácter residencial y mejorar la calidad de vida (PATRICIOS, 2002: 72).

\section{Conclusiones: la modernidad fragmentada de la Ciudad de México}

Mario Pani fue un urbanista visionario que encarnó el espíritu, hasta cierto punto ingenuo, de la modernidad. Tratando de contrarrestar los efectos perversos de la urbanización acelerada del siglo veinte, Pani diseñó con la mejor de sus capacidades entornos espaciosos, pensados para el habitante contemporáneo y con soluciones que permitieron canalizar las inversiones públicas, tratando de lograr la mejor calidad posible del entorno a pesar de la escasez de recursos.

Colaborando siempre con destacados artistas como los muralistas Carlos Mérida, David Alfaro Siqueiros y José Clemente Orozco, en sus proyectos habitacionales intentó, por una parte, contribuir a la gran discutida "integración plástica", y por la otra, elevar los estándares constructivos, estilísticos y de servicios en beneficio de la población residente al utilizar los recursos derivados del ahorro por la escala de dichas intervenciones. No obstante, en 1985 se harían evidentes las limitaciones constructivas y de gestión, cuando un terremoto de alta gradación azotara la Ciudad de México con un elevado costo de vidas, afectando considerablemente las estructuras de muchos de los edificios, cuestionando así la validez del modelo urbano de altura como herramienta para hacer ciudad.

Si bien Mario Pani fue generoso al invitar a arquitectos, ingenieros y artistas a colaborar en sus proyectos, su visión sería como la de los grandes creadores del siglo diecinueve y veinte, en donde la concepción del proyecto surgía de una persona como acto creador único y a partir de ella es que otros colaboradores eran llamados a participar. El "sentido de comunidad" referido por Pani no surgiría de la abstracción de un plan o de un proyecto urbano, sino de la apropiación social de la visión que sustentaría el proyecto. La ciudad como un agregado de piezas ensambladas no lograría articularse de manera orgánica como muchos urbanistas imaginaron. Las "células urbanas" requirieron de sistemas centralizados que las interconectaran para lograr que el "organismo urbano" funcionara adecuadamente. La cohesión comunitaria se basa necesariamente en el control social del espacio, en donde los residentes están suficientemente motivados para intervenir en el entorno y asegurar un desarrollo social armónico. La escala excesiva utilizada en los desarrollos habitacionales (en Tlatelolco, cien mil personas habitaban en densidades de hasta mil habitantes por hectárea), la uniformización del entorno y la falta de flexibilidad dentro de las viviendas provocó que hubiera mucha movilidad entre los residentes, lo cual evitaría la creación de vínculos, formación de redes sociales y de un sentimiento de arraigo en el territorio.

La propuesta de Pani tendría la idea de recuperar el modelo de barrio como célula madre de la ciudad. El modelo en realidad repite el esquema de Supermanzana, pero enfatizando, entre otras cosas, la inversión privada, la captación de aguas pluviales y el uso del suelo mixto (PANI, 1988). El modelo tiene algunas limitaciones conceptuales, sobre todo ya en la etapa posmoderna, como sería centrar la vida comunitaria alrededor de un jardín central tradicional, así como la integración de equipamientos como centros comunitarios, clínicas, talleres y guarderías que responden más a un esquema estatizado de provisión de vivienda tradicional que a un emprendimiento privado atractivo para inversionistas. Este modelo de barrio con su alameda o "estancia para la comunidad", espacios de reunión comunitaria, locales para oficios dentro de un marco de concertación de intereses recuerda más a los prototipos desarollados en la Rusia posrevolucionaria que a las soluciones espaciales de finales del siglo veinte.

Cabe destacar que, para los gobiernos de América Latina, los beneficios de la nueva arquitectura resultaron igualmente atractivos: grandes proyectos de vivienda social a bajo costo, infraestructuras y equipamientos de gran monumentalidad, así como la proyección de una nueva imagen como país joven, dinámico, con una infraestructura industrial creciente y con una economía en continua expansión. La urbanización como instrumento de desarrollo fue ampliamente utilizado, sin embargo, también originó fuertes desigualdades, divisiones espaciales y segregación del tejido social.

Algo que pasaron por alto estos urbanistas fue que en América Latina la modernidad generó un 
proceso dual: mientras las élites se apropiaban cada vez más del concepto de progreso, entendido como la construcción de una nación próspera y moderna mediante la planeación del desarrollo, los conceptos de cambio social y redistribución del ingreso se fueron marginalizando cada vez más; dichos grupos se apropiaron entonces de la planeación como instrumento de cambio social, para enfocarlo al crecimiento económico en abstracto.

La planeación se constituyó entonces en un referente institucional que estableció modelos conductuales respecto a los requerimientos del medio circundante; de acuerdo con una aproximación científica, esta estructura de procedimientos prescindiría de la opinión ciudadana en la toma de decisiones y se institucionalizaba así la burocratización de la vida cotidiana (GEHLEN, 1993). La fragmentación de la realidad urbana, materializada en la división planificada del espacio, estuvo sustentada en los principios de la planeación científica que dio lugar al funcionalismo urbano, utilizado en América Latina por los grupos de poder como instrumento de control y dominación. De este modo, la imagen del desarrollo y el progreso como camino a seguir para lograr el enriquecimiento y consumo generalizado, demostró su insuficiencia sistemática para resolver los problemas materiales y, sociales de la ciudad. El urbanismo funcionalista, que tomaba como punto de partida la división del territorio antes que la integración del mismo, tuvo como consecuencia la fragmentación del espacio, la segregación social y la institucionalización de estos mecanismos mediante la planeación científica. Por tanto, el cambio de paradigmas del periodo referido, radicaría en la incorporación de la complejidad, la yuxtaposición y la simultaneidad de los procesos socioeconómicos y urbanos en la planeación como instrumento de equilibrio. En este sentido, Mario Pani utilizó las metáforas urbanas como poderosas herramientas para pensar, $y$ después transmitir a los tomadores de decisiones, los complejos modelos de ciudad que proponía, siendo esto determinante para que fuera comisionado a realizar los proyectos urbanos que definirían la modernidad en la Ciudad de México de mediados del siglo $X X$.

\section{Bibliografía}

BIRCH, E. L. (1980): "Radburn and the American Planning Movement. The persistence of an idea", (Charles Ascher to Edith Elmer Wood, February 6 , 1928, Edith Elmer Collection, Avery Library, Columbia University). Journal of the American Planning Association 46: 4.
Cohen, J. L. (1987): Le Corbusier et la mystique de I'URSS. Theories et projets pour Moscou 1928-1936, Liege, Pierre Mardaga Éditeur.

CostA, L. (1995): Registro de una vivência, Saõ Paolo, Empresa das Artes.

FISHMAN, R. (1977): Urban Utopias in the twentieth Century: Ebenezer Howard, Le Corbusier and Frank Lloyd Wright, New York, Basic Books.

Fox Weber, N. (2008): Le Corbusier: A Life, New York, Alfred A. Knopf.

Geddes, P. (1915): Cities in evolution. An introduction to the Town Planning Movement and to the Study of Civics, London, Williams and Norgate.

Gehlen A. (1993): Antropología filosófica. Del encuentro y descubrimiento del hombre por sí mismo, Paidós, Barcelona.

GÓMEZ MAYORGA, M. (1949): "El problema de la habitación en México. Realidad de su solución: una conversación con el Arq. Mario Pani”, Arquitectura/México No. 27: 67-74.

GRopIUs, W. (1950): "The sociological premises for the minimum dwelling of urban industrial populations", The scope of total architecture, New York, Harper: 104-118.

LaKoff, G., \& Johnson, M. (1980): Metaphors We Live $B y$, Chicago, The University of Chicago Press.

Le CoRbusier (1929): The city of tomorrow and its planning, London, John Rodher. Trad. por F. Etchells de L'Urbanisme, $8^{\mathrm{a}}$. Edición, [1947], London, Architectural Press.

- (1933): The Radiant City, London, Faber and Faber.

- (1967): Elements of a doctrine of urbanism to be used as the basis of our machine-age civilization, Orion Press, New York.

MUMFORD, L. (1951): Foreword, en Stein, Clarence, Towards New Towns for America, Chicago, The University Press of Liverpool.

Nuessel, F. (2010): Figurative Language: Semiotics. en A. BARbeR \& R. J. Stainton (Eds.) Concise Encyclopedia of Philosophy of Language and Linguistics, Amsterdam, Elsevier.

PANI, M. (1957): "Satélite. La ciudad fuera de la ciudad", Arquitectura/México No. 60, Diciembre, Tomo 13: 198-226.

- (1957): "México. Un problema. Una solución", Arquitectura México No. 60 diciembre: 198-226.

- (1960): "Conjunto Urbano Nonoalco-Tlatelolco. Regeneración Urbanística de la ciudad de México", Arquitectura/México No. 72, Año XXII, Tomo XVI, Diciembre: 183-224.

- (1973a): "Problemas Urbanísticos. El automóvil destructor de la ciudad de México", Arquitectura/ México No. 109: 5-7.

- (1973b): "Problemas Urbanísticos. La Célula Urbana", Arquitectura/México No. 108, Año XXVI, Tomo 28: 236.

- 1988): Ciudad Concertada. Tesis sobre el reordenamiento urbano de la Ciudad de México. En colaboración con Manuel LAROSA \& Angel BoRJA. México, mimeografiado.

PAtRICIOS, N. (2002): "The neighborhood concept: a retrospective of physical design and social interaction", Journal of Architecture and Planning Research 19 (1): 70-90 
Estudios

Perry, C. (1929): "The Neighborhood Unit, en Neighborhood and community Planning". Regional Survey VII, Committee on the Regional Plan of New York, New York, Regional Plan of New York and its Environs.

SERT, J. L. (1942): "Biology of cities", Time Magazine, 30 Noviembre,
Metáforas de la modernidad: Mario Pani en México

Alfonso Valenzuela-Aguilera

http://www.time.com/time/magazine/ article/0,9171,766697,00.htm

[consultado el 05/06/2018].

Xavier, A. (1987) (Ed.): Arquitetura Moderna Brasileira: Depoimento de uma Geração, São Paolo, Associação Brasileira de Ensino de Arquitetura / Fundação Vilanova Artigas / PINI. 